\title{
Spatial and temporal genetic variation in Ethiopian barley (Hordeum vulgare L.) landraces as revealed by simple sequence repeat (SSR) markers
}

\author{
Allo A. Dido ${ }^{1,2}$, Dawit T. Degefu ${ }^{3}$ Ermias Assefa ${ }^{1}$, M. S. R. Krishna ${ }^{2}$, B. J. K. Singh² and Kassahun Tesfaye ${ }^{1,4^{*}}$
}

\begin{abstract}
Background: Ethiopia is considered as center of diversity for barley (Hordeum vulgare L.) and it is grown across different agro-ecologies of the country. Unraveling population structure and gene flow status on temporal scales assists an evaluation of the consequences of physical, demographic and overall environmental changes on the stability and persistence of populations. This study was to examine spatial and temporal genetic variation within and among barley landrace samples collected over a period of four decades, using simple sequence repeat markers.
\end{abstract}

Results: Results from STRUCTURE, neighbor joining tree and discriminant analysis of principal component (DAPC) analysis revealed presence low-to-high genetic diversity among the landraces and grouped the landraces into three clusters. The cluster analysis revealed a close relationship between landraces along geographic proximity with genetic distance increases along with geographic distance. From analysis of molecular variance (AMOVA) in terms of collection year, it was observed that within-population genetic diversity much higher than between population and that the temporal differentiation is considerably smaller. The low-to-high genetic differentiation between landraces could be attributed to gene flow across the region as a consequence of seed exchange among farmers.

Conclusion: The results demonstrate that this set of SSRs was highly informative and useful in generating a meaningful classification of barley germplasms. Furthermore, results obtained from this study also suggest that landraces are a source of valuable germplasm for sustainable agriculture in the context of future climate change and in situ conservation strategies following adaptation to local environments.

Keywords: Barley, Diversity, Landraces, Simple sequence repeats (SSR), Spatial, Temporal

\section{Introduction}

In plant natural populations, genetic structure is mainly influenced by the species breeding system, gene flow, genetic drift and natural selection [1]. In addition, changes in climate and/or geology (geography) can also led to shifts in the genetic composition of a population

\footnotetext{
*Correspondence: kassahun.tesfaye@aau.edu.et

${ }^{1}$ Ethiopian Biotechnology Institute, P. O. Box 5954, Addis Ababa, Ethiopia

Full list of author information is available at the end of the article
}

through creating spatial and/or temporal heterogeneity in the environments [2].

Recently, an increase in climate variability has led to instabilities in agricultural production systems across the globe, sometimes leading to food shortages and unexpected rises in food prices [3, 4]. To alleviate this phenomenon, it is necessary to build sustainable systems that can ensure food security through the stabilization of agricultural production [5]. Genetic variability for traits involved in response to changes in environmental conditions and local adaptation are one of the processes 
leading to a phenotypic differentiation of populations [6] and a locally adapted population shows greater fitness in its environment compared to populations from other environments [7].

Despite a narrow genetic background, modern plant breeding activities in the recent decades resulted in the development of a large number of elite varieties with a higher yield, better quality and resistance to stresses [8]. Replacement of highly adapted landraces by modern varieties performing under optimal conditions but failing under harsh environments resulted in the disappearance of most landraces of crop plants from practical farming [8-10]. Landraces are genetically heterogenous and dynamic populations of a cultivated species associated with traditional farming systems [11], while locally adapted and genetically distinct, they usually lack a history of formal crop improvement. Landraces are a critical element of food security and in many regions of the world, the cultivation of landraces is still common, in particular in the centers of crop diversity [12-14] and are used in breeding due to their unique variability in regard to adaptive traits $[15,16]$.

Though in many countries, landraces were replaced by improved cultivars, in some countries, to use an advantage of the specific adaptations of landraces to the agroecosystem, their cultivation is still ongoing [17-19] and in Ethiopia, they comprise more than $90 \%$ of the barley cultivated [20]. The landraces of self-pollinated species such as barley harboring the chromosomal regions consisted of blocks of genes with a low frequency of recombination which may confer a specific adaptation to specific environments [21]. This shows that the landraces are ideal association panels to identify genes controlling adaptive traits in crop species [22].

Therefore, for efficient utilization of barley landraces in breeding programs and to develop the strategies for their optimal conservation, it is necessary to systematically evaluate genetic diversity and population structure encompassed in the landraces collections following spatial and temporal pattern [23]. Of the DNA markers available, simple sequence repeat (SSR) markers have been widely utilized to analyze population structure and genetic diversity in barley germplasm, due to the high polymorphism, reproducibility, co-dominant and multiallelic nature when compared to most of the marker systems [24-28].

Efforts have been made over the last three decades to assess crop genetic diversity using molecular marker technologies and have generated considerable knowledge about the extent and nature of genetic diversity present in conserved and/or actively utilized germplasm of various crops [29]. Understanding the distribution of genetic variation within populations is fundamental for the management of species, particularly in a rapidly changing world [30]. Those changes which are induced due climatic factors in the spatial distribution and phenology of populations can influence numerous aspects of demography including dispersal, survival, reproductive success, and overall abundance, all of which have consequences for the distribution of genetic variation within and among populations [31, 32].

Our objective in the present study is threefold. Firstly, we investigated the genetic diversity and population structure of samples covering four decades. We analyzed temporal stability of genetic differentiation among barley samples. Secondly, we evaluated the influence of time on genetic stability by comparing temporal genetic variance among individual in different collection time periods. Lastly, we tested whether demographic imbalances have caused changes in genetic diversity, population structure and relationship (connectivity) by analyzing gene flow in four temporal replicates of five regional sets.

\section{Materials and methods Plant materials}

A total of 376 barley landraces and eight improved cultivars (hereafter considered as genotypes) were selected from 585 landraces and 10 cultivars obtained from Ethiopian Biodiversity Institute (EBI) and Sinana Agricultural Research Center (SARC), respectively, for SSR genotyping, population structure, spatial and temporal analysis. For data analysis, the improved varieties were grouped for diversity assessment, while each variety included in the clustering analysis individually. As indicated above, the 376 landraces were selected from 585 landrace collections from different agro-ecological regions of Ethiopia using random sampling techniques and categorized into two-rowed, six-rowed and irregular types based on kernel row number. The altitude of the collection sites for the landraces used in this study ranged from 1430 to $2950 \mathrm{~m}$ above sea level. Based on altitude of the collection sites, these 376 materials were categorized into four classes: Altitude class I $(<1500 \mathrm{~m})$, Altitude class II (1501-2000 m), Altitude class III (2001-2500 m) and Altitude class IV (>2500 m); while released varieties are excluded from the analysis. The landraces were collected over 41 years, ranging from1976 to 2017 and conserved at ex situ genebank EBI in Ethiopia.

\section{Description of experimental site}

The field experiments were conducted during 2018 and 2019 main cropping seasons at Sinana Agricultural Research (SARC) on-station and at Bale-Goba on-farm research sites, Bale zone, Oromia regional state, southeast Ethiopia. Both areas represent the highest altitude for barley production areas and have bimodal rainfall 
pattern. SARC is located at $7^{\circ} 7^{\prime} \mathrm{N}$ latitude, $39^{\circ} 40^{\prime} \mathrm{E}$ longitude, 2,400 masl, representing high altitude of barley production areas. The area is characterized by Vertisol soil type, with $\mathrm{pH}$ ranging from 6.3 to 7.0 (slightly acidic) at a soil depth of $0-15 \mathrm{~cm}$. SARC experiences an annual average temperature of 9.42 and $21.16{ }^{\circ} \mathrm{C}$ and annual rainfall totals of between 452.7 and $1129.5 \mathrm{~mm}$, respectively. Bale-Goba, which is an on-farm experimental site of SARC, is located at $7^{\circ} 0^{\prime} \mathrm{N}$ latitude and $39^{\circ} 59^{\prime} \mathrm{E}$ longitude and altitude is 2,743 masl. The area soil is characterized as pellic and chromic vertisol.

\section{Genotyping by SSR markers}

Genomic DNA was extracted by the CTAB method [33] from fresh leaves of sampled individuals. A total of 10 single individual per accession were sampled and bulked for genomic DNA extraction. A total of 49 SSR markers were selected for analysis, covering the seven chromosomes of barley genome.

\section{Genetic diversity analysis}

For each region (locality) and each year, summary statistics, such as allele number per locus $(\mathrm{Na})$, number of effective allele (Ne), Shannon's information index (I) [34], gene diversity (GD, [35], polymorphic information content (PIC) [36], observed heterozygosity (Ho) and the expected heterozygosity $(\mathrm{He})$ [37], heterozygosity expected under Hardy-Weinberg equilibrium that accounts for both the number and the evenness of alleles), allele richness (Ar) [38], inbreeding coefficient (Fis) and the fixation index $\left(\mathrm{F}_{\mathrm{ST}}\right)$ [39] among populations were calculated using GeneAlEx $6.51 \mathrm{~b} 2$ software and the hierfstat $\mathrm{R}$ package [40]. The proportion of the total genetic variance contained in a subpopulations $(F s t)$ relative to the total genetic variance was computed within each year also using hierfstat.

\section{Inter-individual genetic distances}

Nei's genetic distance [41] was calculated and used for unrooted phylogeny reconstruction based on UPGMA methods as implemented by PowerMarker software and the tree was visualized using MEGA-X version 10.2.2 [42]. The inter-individual genetic distances was calculated using principal components analysis (PCA) using adegenet [43]. Principal coordinate analysis (PCoA) was carried out in GeneAlEx version 6.51b2 [44] and analysis of molecular variance (AMOVA) was calculated by $R$ package poppr [45].

Linear regression analysis of the PIC, Shannon Wiener index and PI with altitude and longitude was conducted using Excel. By inverting Wright's formula [46], the value of $\mathrm{Nm}$ can be estimated from $F_{S T}$, as $\mathrm{Nm}=\left(1-F_{S T}\right) / 4 F_{S T}$, where ' $\mathrm{N}$ ' is the size of each population and ' $\mathrm{m}$ ' is the migration rate between populations. This approach is effective to estimate gene flow indirectly.

\section{Spatio-temporal genetic variation}

To evaluate the effects of sampling sites and year of sampling on patterns of genetic variation, we performed a permutation-based multivariate analysis of variance by using the function adonis of the vegan package [47] in $R$. This method partitions sum of squares for distance matrices in a manner similar to AMOVA, but allows for both nested and crossed factors [48]. We also evaluated the effects of sampling sites and year of sampling as cross check factors on the matrix of individual genetic distances. Statistical significance was assessed using 9,999 permutations and given the signal of temporal variability observed, subsequent analyses were done for each year separately.

Due to variation in the number of sampling sites and the number of individuals sampled per site among years, we performed a rarefied bootstrap to normalize for the minimum number of sites per year and the minimum number of individuals per site to ensure that there was no bias due to the unbalanced sampling. We subsampled the data keeping only 12 sites per year and 5 individuals per site and performed the analysis of molecular variance (AMOVA).

\section{Clustering analysis}

In this study, we searched for genetic groups using discriminant analysis of principal components (DAPC) implemented in the adegenet [43] package in R. DAPC maximizes differences among clusters while minimizing variation within but does not rely on a particular population genetic model, such as Hardy-Weinberg equilibrium, which is unrealistic for out breeding populations [49]. For each year, we used the function find.clusters to determine the number of clusters and also Bayesian information criterion $(B I C)$ was used to identify the most probable number of clusters $(K)$ present in the data. Discriminant analysis of principal component (DAPC) provides membership probabilities to these clusters for each individual, which we examined for geographic structure.

\section{Isolation by distance (IBD)}

Isolation by distance (IBD) has been a common measure of genetic structure among populations and is based on Euclidean distances among populations. The effect of migration-selection-drift equilibrium on population structure is governed by spatial or environmental differences is usually elucidated by isolation-by-distance (IBD). We evaluated for IBD by testing the correlation between genetic distance and the geographic Euclidean distance between all pairs of individuals. This is because, 
the Euclidean distance between two points in Euclidean space is the length of a line segment between the two points and it can be calculated from the Cartesian coordinates of the points. Significance of the correlation between the two distance matrices was assessed by a Mantel test using the mantel.randtest function of the ade4 $\mathrm{R}$ package with 9,999 permutations [50]. To test IBD, the genetic distance was used as the response, the geographic distance as the predictor, and the environmental distance as the condition factor.

\section{Spatial structure analysis}

The combination of genetic and geographic information can improve our ability to identify loosely differentiated populations and can give us precise spatial locations of genetic barriers or hidden clusters [51]. Given the weak overall structure (i.e., clusters and IBD; see above), we also tested for cryptic spatial genetic structure within each year using spatial principal component analysis (spca; [52]. As suggested by Jombart et al. [52], this spatial multivariate method employs Moran's index $(I)$ of spatial autocorrelation [53] to detect global structures. We used the spca function employed in the adegenet [52] of $R$ package. We used the inverse distance analysis method for testing linkages in the system, given that: (a) sampling sites were unevenly spread over the study area; (b) we had no a priori hypothesis about their connectivity. Significance was checked using permutation test $(n=9999)$ [52].

\section{Results}

\section{Population genetic diversity}

The PIC (Polymorphic Information Content) is an indicator of the level of polymorphism and it ranges between 0 and 1 among the populations under study. As shown in Table 1, relatively medium levels of genetic diversity were observed in Ethiopian barley populations with average value of 0.552 . Based on the regions of origin, the PIC values varied from 0.474 (SNNP) to 0.652 (Oromia). For altitude classes it ranged from 0.374 (Altitude class I) to 0.504 (Altitude class III). The Shannon's information index incorporates the following two factors: species richness and the equitability or evenness of individual distributions. Among all the populations, based on regions of origin, the index ranged from 0.463 (B/ Gumuz) to 0.615 (Oromia). The PIC and Shannon levels of the populations showed increasing trend with altitude, but tend to decline at highest altitude (Table 1).

Nei's gene diversity (h) values calculated was greater than 0 for all the populations, ranging from 0.301 (B/ Gumuz) to 0.426 (Oromia). The observed heterozygosity (Ho) for regions of origin, ranged from 0.594 (Oromia) to 0.662 (Amhara) and the expected heterozygosity $(\mathrm{He})$ ranged from 0.688 (Amhara) to 0.773 (Tigray). The subpopulation genetic variance fixation index $\left(\mathrm{F}_{\mathrm{ST}}\right)$ is a measure of population differentiation due to genetic structure. Its value ranged from 0.034 (B/Gumuz) to 0.082 (Oromia) based on regions of origin, from 0.053 (Altitude class I) to 0.082 (Altitude class III) based on altitude classes and from 0.011 (Year IV) to 0.056 (Year I) in terms of year of collection (Table 1). Taking all indicators into account, samples collected from Oromia had relatively high genetic diversity but this should be confirmed using the same sample size with more powerful marker like SNP. Frequency calculations for all SSR marker based genetic distance calculated as expected heterozygosity $(\mathrm{He})$, polymorphic information content (PIC), major allele frequency (MAF) and number of private (unique) allele (Npa) are shown in a column graph in the range of $0.2-0.8,0.1-0.9,0.3-0.8$ and $0-6$, respectively (Fig. 1A-D).

\section{Spatio-temporal genetic variation partitioning}

From a permutation-based multivariate analysis of variance, we observed a significant interaction effect among regions of origin and altitude classes $\left(F_{12,925}=10.98\right.$, $p<0.001)$, region and years of collection $\left(F_{12,925}=20.77\right.$, $p<0.001)$ and region, altitude and year $\left(F_{36,925}=13.42\right.$, $p<0.001$ ) (Additional file 1: Table S1) on barley genotypes genetic variation. However, the interaction effect of altitude and year was non-significant $\left(\left(F_{9,925}=7.02\right.\right.$, $p=0.157)$. The result of rarefied bootstrap approach indicated that with a standardized number of sites per year and number of individuals per region, the effect of the year and the region were significant in 100\% of the 9999 replications. The effect of the interaction was significant in $70 \%$ of the replications.

The frequency of loci that were polymorphic in all the five barley populations in year category I, II, III, IV and in overall years was 96.43, 93.58, 94.71, 95.61 and 96.59\%, respectively. The percentage of polymorphic loci $(P P L)$ and gene diversity (expected heterozygosity; $\mathrm{He}$ ) values for each of the five studied barley populations are given in Table 2. In all year categories, higher $P P L$ values were found in the populations from Oromia, Amhara and Tigray and also had higher gene diversity values than population from SNNP and B/Gumuz. On the other hand, gene diversity values did not differ significantly between years (Table 2). Those populations from Oromia, Amhara and Tigray regions, the high $P P L$ was accompanied by a high value of $H e$ and in population SNNP and B/Gumuz lower PPL was accompanied by a lower value of $H e$. In the year I and II category, there were more unique alleles per population than in Year III and IV.

Analysis of molecular variance (AMOVA) on genetic differentiation among and within regions of origin, 


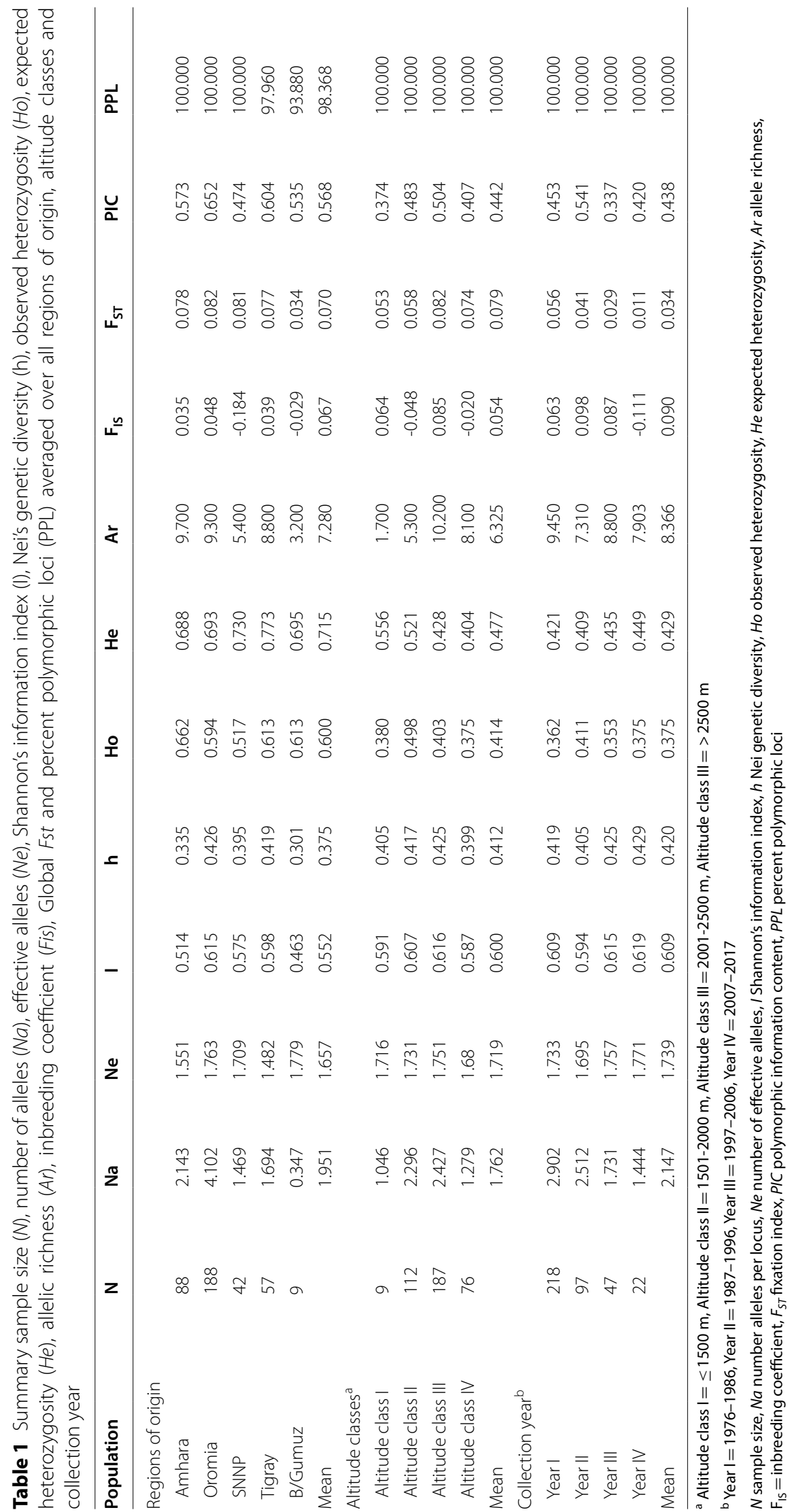




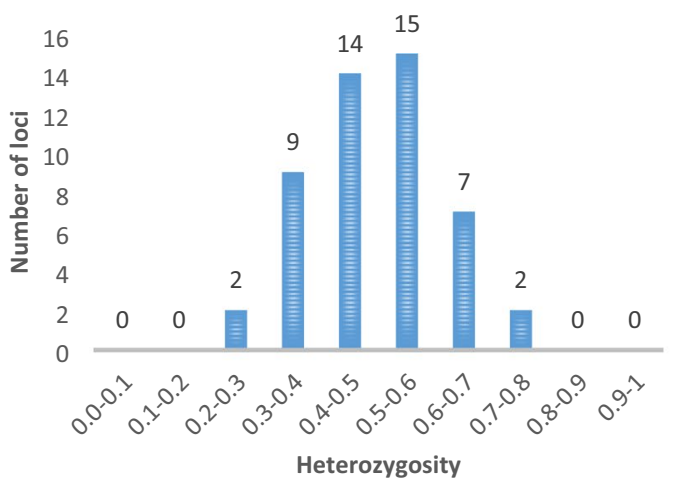

(A)

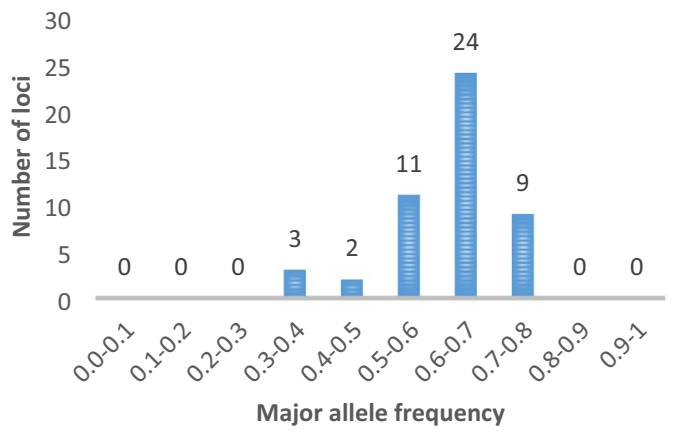

(C)

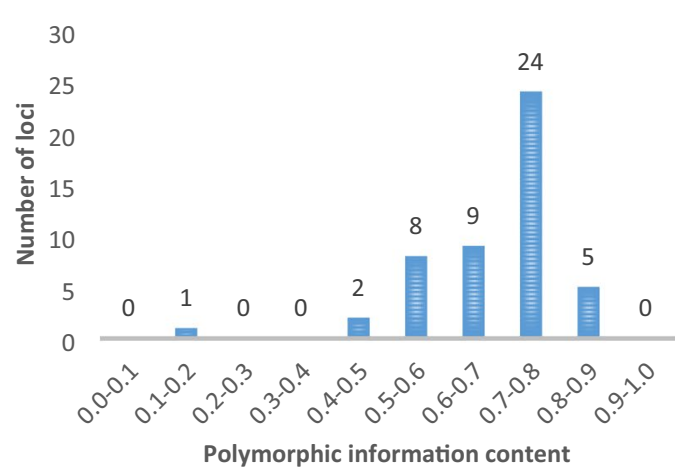

(B)

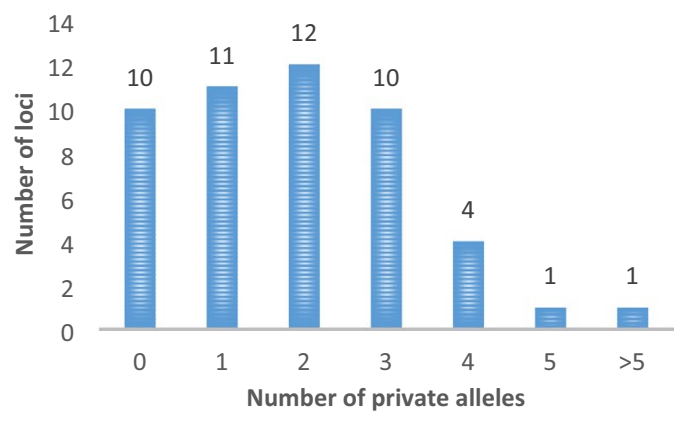

(D)

Fig. 1 Distribution of genetic diversity for 49 SSR markers in the 384 barley (Hordeum vulgare L.) genotypes. A Gene diversity (GD) or expected heterozygosity (He), B polymorphic information content (PIC), $\mathbf{C}$ major allele frequency (MAF) and $\mathbf{D}$ number of private (unique) allele

Table 2 Genetic diversity estimates for five barley populations in four decades (1976-2017)

\begin{tabular}{|c|c|c|c|c|c|c|c|c|c|c|c|c|}
\hline \multirow[t]{2}{*}{ Population } & \multicolumn{3}{|l|}{$\begin{array}{l}\text { Year I } \\
(1976- \\
1986)\end{array}$} & \multicolumn{3}{|l|}{$\begin{array}{l}\text { Year II } \\
(1987- \\
1996)\end{array}$} & \multicolumn{3}{|l|}{$\begin{array}{l}\text { Year III } \\
(1997- \\
2006)\end{array}$} & \multicolumn{3}{|l|}{$\begin{array}{l}\text { Year IV } \\
(2007- \\
2017)\end{array}$} \\
\hline & $N$ & PPL & $\mathrm{He}$ & $N$ & PPL & $\mathrm{He}$ & $N$ & PPL & $\mathrm{He}$ & $N$ & PPL & $\mathrm{He}$ \\
\hline Oromia & 128 & 0.983 & $0.637 a$ & 37 & 0.973 & $0.611 a$ & 12 & 0.974 & 0.598 & 11 & 0.966 & 0.603 \\
\hline Amhara & 45 & 0.987 & $0.589 b c$ & 14 & 0.967 & $0.577 b$ & 26 & 0.951 & 0.573 & 3 & 0.951 & 0.592 \\
\hline SNNP & 24 & 0.892 & $0.547 d$ & 12 & 0.832 & $0.539 c$ & - & - & - & 6 & 0.901 & 0.563 \\
\hline Tigray & 12 & 0.952 & $0.603 b$ & 34 & 0.977 & $0.598 \mathrm{ab}$ & 9 & 0.879 & 0.561 & 2 & 0.955 & 0.595 \\
\hline B/Gumuz & 9 & 0.938 & $0.505 c$ & - & - & - & - & - & & - & - & - \\
\hline Mean & & 0.945 & 0.576 & - & 0.937 & 0.581 & - & 0.935 & 0.577 & - & 0.943 & 0.588 \\
\hline
\end{tabular}

$N$ sample size, PPL proportion of polymorphic loci within each population, He gene diversity; He values of the same year followed by same letter are not significantly different, $(P<0.05)$; means of $P$ and $H e$ of the four year classes were tested by the t test and found not significantly different

altitude classes, and observed clusters (subgroups) of barley genotypes was conducted and the results are shown in Table 3. Findings from AMOVA revealed that 89, 84 and $81.70 \%$ of total genetic variations were contributed by differences within regions of origin, altitude classes and clusters, respectively, while only 11, 6 and $18.30 \%$ of total genetic variation was due to differences among regions of origin, altitude classes and clusters, respectively, significantly lower than among other populations.

$\mathrm{F}_{\mathrm{st}}$ and $\mathrm{Nm}$ values were $0.054(p<0.001)$ and 4.380 for regions of origin of barley population, 0.049 and 4.852 for altitude classes and 0.071 and 3.271 for clusters (Table 3).

Based on year of collection (portioned into four categories), between-populations diversity was estimated as 
Table 3 Analysis of molecular variance (AMOVA) within/among 384 barley genotypes based on 49 SSR data according to regions of origin, altitude classes and collection years

\begin{tabular}{|c|c|c|c|c|c|c|c|}
\hline Source & df & SS & MS & Est. Var & $\%$ & $\mathrm{~F}_{\mathrm{ST}}$ & $\mathrm{Nm}$ \\
\hline \multicolumn{8}{|c|}{ Based on regions of origin } \\
\hline Among populations & 4 & 353.182 & 88.296 & 1.219 & $11 \%$ & $0.054^{* *}$ & 4.380 \\
\hline Within populations & 379 & 3601.539 & 9.503 & 9.503 & $89 \%$ & - & - \\
\hline Total & 383 & 3954.721 & - & 10.722 & $100 \%$ & - & - \\
\hline \multicolumn{8}{|l|}{ Based on altitude classes } \\
\hline Among populations & 3 & 28.246 & 9.415 & 0.000 & $16 \%$ & $0.049^{* *}$ & 4.852 \\
\hline Within populations & 380 & 3926.476 & 10.333 & 10.333 & $84 \%$ & - & - \\
\hline Total & 383 & 3954.721 & - & 10.333 & $100 \%$ & - & - \\
\hline \multicolumn{8}{|l|}{ Based on cluster } \\
\hline Among populations & 2 & 384.451 & 192.226 & 2.607 & $18.30 \%$ & $0.071^{* *}$ & 3.271 \\
\hline Within populations & 381 & 5921.601 & 15.542 & 15.542 & $81.70 \%$ & - & - \\
\hline Total & 383 & - & - & 18.149 & $100 \%$ & - & - \\
\hline
\end{tabular}

Df degrees of freedom, SS sum of squares, Var. variance

shown in Table 4. The between-populations diversity in all year categories (I to IV) showed a moderate value of $15.77,17.19,12.57$ and $13.44 \%$ of variance, respectively. On the other hand, the within-populations genetic diversity was $84.23 \%$ for the Year-I, $82.81 \%$ for Year-II, $87.43 \%$ for Year-III and $86.56 \%$ for Year-IV, all were much larger than the between-populations genetic diversity (Table 4).

Genetic differentiation and gene flow among populations $\mathrm{F}_{\mathrm{ST}}$ ranging from 0.00 to 0.05 indicates low genetic differentiation between populations; $\mathrm{F}_{\mathrm{ST}}$ ranging from 0.05 to
0.15 indicates moderate genetic differentiation between populations; $\mathrm{F}_{\mathrm{ST}}$ ranging from 0.15 to 0.25 indicates large genetic differentiation between populations; and $\mathrm{F}_{\mathrm{ST}}$ greater than 0.25 indicates strong genetic differentiation between populations [54]. The pairwise $\mathrm{F}_{\mathrm{ST}}$ between pairs of the five regions, as shown in Table 5, ranged from 0.033 (Amhara with Oromia) to 0.348 (Tigray with $\mathrm{B} /$ Gumuz), with an average of 0.145 , which indicated presence of differences among barley populations. The analysis indicate that genetic variation occurred within populations rather than among populations. The degree

Table 4 Analysis of variance (AMOVA) of spatial and temporal genetic diversity estimates based on 49 SSR markers in five barley populations and 4 decades (1976-2017)

\begin{tabular}{|c|c|c|c|c|c|}
\hline Year & Sources of variation & df & SS & Var & $\%$ of variance \\
\hline \multirow[t]{3}{*}{ Year I } & Between populations & 4 & 2037.11 & 17.56 & 15.77 \\
\hline & Within populations & 213 & $13,142.56$ & 61.70 & 84.23 \\
\hline & Total & 218 & $15,179.67$ & 79.26 & 100.00 \\
\hline \multirow[t]{3}{*}{ Year II } & Between populations & 3 & 2149.27 & 19.32 & 17.19 \\
\hline & Within populations & 93 & 7056.32 & 75.87 & 82.81 \\
\hline & Total & 96 & 9205.59 & 95.19 & 100.00 \\
\hline \multirow[t]{3}{*}{ Year III } & Between populations & 2 & 154.64 & 23.12 & 12.57 \\
\hline & Within populations & 44 & 6507.12 & 147.89 & 87.43 \\
\hline & Total & 46 & 6661.76 & 171.01 & 100.00 \\
\hline \multirow[t]{3}{*}{ Year IV } & Between populations & 3 & 105.19 & 21.02 & 13.44 \\
\hline & Within populations & 18 & 1231.27 & 68.40 & 86.56 \\
\hline & Total & 21 & 1336.36 & 89.42 & 100.00 \\
\hline \multirow[t]{4}{*}{ All pops. in all years } & Between years & 3 & 2011.67 & 7.08 & 3.15 \\
\hline & Between populations with in years & 10 & 3210.07 & 20.26 & 14.81 \\
\hline & Within populations & 370 & 9037.41 & 88.47 & 82.04 \\
\hline & Total & 383 & $14,259.15$ & 108.72 & 100.00 \\
\hline
\end{tabular}

$d f$ degrees of freedom, SS sum of squares, Var. variance 
Table 5 Pairwise $F_{S T}$ values and Nm values based on 999 permutations from AMOVA according to regions of origin and altitude classes (all $\mathrm{F}_{\mathrm{ST}}$ values were significantly greater than $0, \mathrm{p}<0.0001$ )

\begin{tabular}{|c|c|c|c|c|c|c|c|}
\hline Regions & & $\mathrm{F}_{\mathrm{ST}}$ & $\mathrm{Nm}$ & Altitude classes* & & $\mathrm{F}_{\mathrm{ST}}$ & $\mathrm{Nm}$ \\
\hline Amhara & Oromia & 0.033 & 7.326 & Altitude class I & Altitude class II & 0.074 & 3.128 \\
\hline Amhara & SNNP & 0.189 & 1.073 & Altitude class I & Altitude class III & 0.128 & 1.703 \\
\hline Amhara & Tigray & 0.045 & 5.306 & Altitude class I & Altitude class IV & 0.307 & 0.564 \\
\hline Amhara & B/Gumuz & 0.081 & 2.836 & Altitude class II & Altitude class III & 0.053 & 4.467 \\
\hline Oromia & SNNP & 0.047 & 5.069 & Altitude class II & Altitude class IV & 0.092 & 2.467 \\
\hline Oromia & Tigray & 0.208 & 0.952 & Altitude class III & Altitude class IV & 0.021 & 11.655 \\
\hline Oromia & B/Gumuz & 0.104 & 2.154 & Cluster & & $\mathrm{F}_{\mathrm{ST}}$ & $\mathrm{Nm}$ \\
\hline SNNP & Tigray & 0.259 & 0.715 & Cluster I & Cluster II & 0.046 & 5.185 \\
\hline SNNP & B/Gumuz & 0.106 & 2.108 & Cluster I & Cluster III & 0.131 & 1.658 \\
\hline Tigray & B/Gumuz & 0.348 & 0.468 & Cluster II & Cluster III & 0.064 & 3.656 \\
\hline
\end{tabular}

*Altitude class I ( $\leq 1500 \mathrm{~m})$, Altitude class II (1501-2000 m), Altitude class III (2001-2500 m) and Altitude class III (>2500 m), $F_{S T}$ Fixation index, Nm number of migrants

of genetic differentiation among the populations that were distributed close to one another, such as Amhara with Oromia, Amhara with Tigray and Oromia with SNNP, was low. On the other hand, regions like, Oromia with B/Gumuz, SNNP with B/Gumuz and Amhara with $\mathrm{B} /$ Gumuz exhibited a moderate level of genetic differentiation. There was strong genetic difference between SNNP with Tigray and Tigray with B/Gumuz populations (Table 5).

The gene flow among the populations based on regions of origin, altitude class and cluster was generally at a high level with mean values for $\mathrm{Nm}$ are 2.801, 3.997 and 3.500, respectively (Table 5 ). All the $\mathrm{Nm}$ values among the populations based on regions of origin are greater than 1, except for Oromia with Tigray and SNNP with Tigray. In addition, gene flow exhibited higher levels among the populations based on altitude classes except for Altitude class I with Altitude class IV.

\section{STRUCTURE model-based population clusters and genetic relationship}

From STRUCTURE model-based simulations carried out by varying $\mathrm{K}$ from 1 to 15 with 3 iterations per $\mathrm{K}$, all 384 accessions, the $\operatorname{LnP}(\mathrm{D})$ value showed evident knees at $K=3$ (Fig. 2A and C). The assignment analysis implemented in the STRUCTURE program and the discriminant analysis of principal component (DAPC), indicated that there are three clustered (sub-grouped) populations in our sampling scheme based on regions of origin, altitude classes and collection years (Fig. 2B and D).

Based on regions of origin, altitude class and subgroups (clusters), Nei's genetic distance was calculated from a pairwise comparison and it varied from 0.025 (Tigray and $\mathrm{B} /$ Gumuz) to 0.159 (Oromia and Amhara), with a mean value of 0.085 , and varied from 0.014 (Altitude class IV and Altitude class I) to 0.060 (Altitude class III and
Altitude class II) with average value of 0.039 (Table 6). From a Mantel test conducted for barley genotypes studied indicated a positive correlation between geographic and genetic distance among populations $(r=0.642$, $P<0.001)$.

\section{Discussion}

Diversity (biodiversity) refers to the presence of variations at genetic, species and ecosystem levels. As to the crop plants, if characterized, evaluated and managed appropriately, these variation can be used in genetic enhancement of current crop performance in terms agronomic traits (specially yield) and resistance to different biotic and abiotic stress factors. As mentioned above, these diversity (genetic diversity) can be used in efforts to address the challenges posed by diverse and changing production systems, particularly in present global changes, in promoting resilience, improving livelihoods and supporting food security and nutrition.

\section{Genetic diversity in landrace populations}

Analysis of genetic relationships in crops species is an important component of crop improvement as it helps to analyze genetic variability of cultivars, select parental materials for hybridization and identify materials that should be maintained to preserve maximum genetic diversity in germplasm. The presence of diversity among accessions and within accessions showed the potential of genetic variation within accessions which is a source material for barley improving purpose [20, 55-63]. The exploitation of within accession variation through pure line selection has proven to provide superior germplasm for yield and disease resistance $[64,65]$. As mentioned in $[55,64]$, exotic cultivars out-yield local landraces under good management practices, but local landraces usually out-yield the exotic material under the low input 




(A)

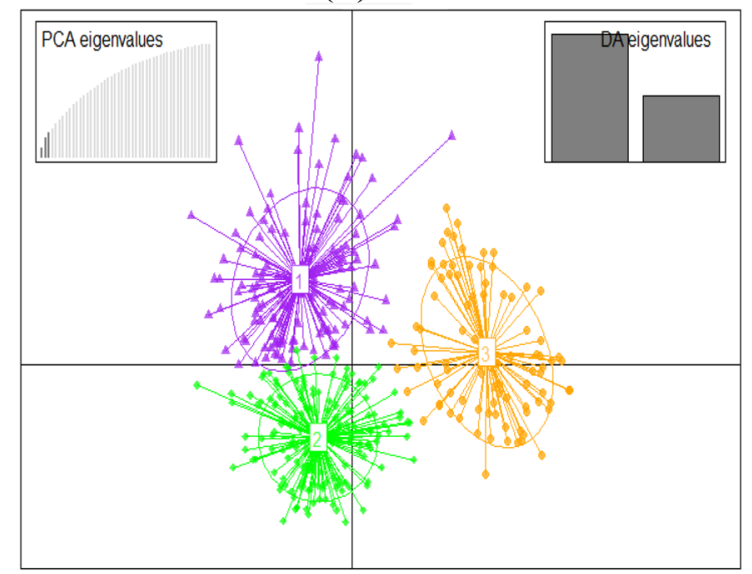

(B)

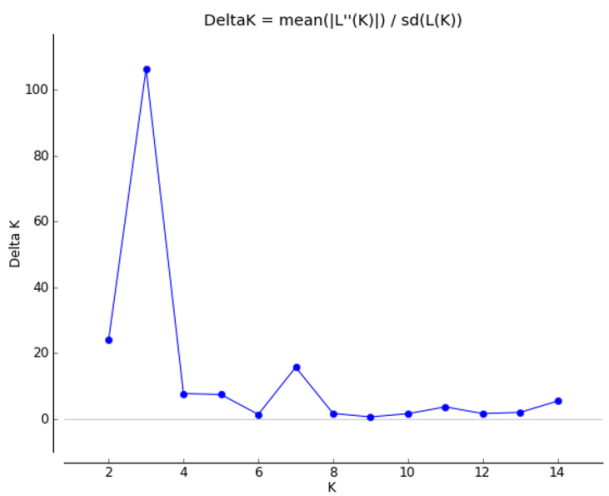

(C)

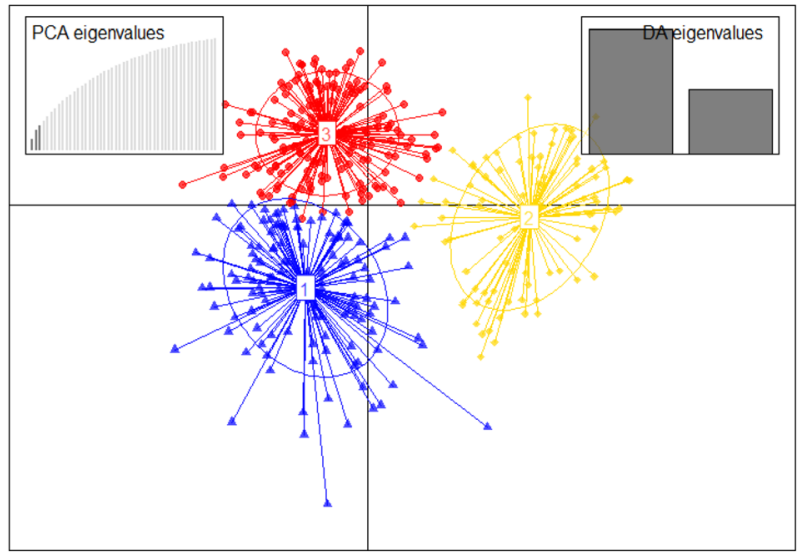

(D)

Fig. 2 The two different methods for determining optimal value of $K$ and inferred population structure of barley genotypes $(\mathbf{A}$ and $\mathbf{C})$ the STRU CTURE output described by Pritchard et al. (2000) for regions of origin and altitude and (B and $\mathbf{D}$ ) the discriminate analysis of principal component (DAPC) to determine number of clusters

conditions which predominate among peasant farms. For such conditions, native germplasm should be exploited to improve the adaptation and productivity of crops. In addition, the presence of genetic diversity among local germplasm could be used as source of breeding materials as reported for barley and other crops [20, 64-68].

In this study, highest barley diversity was observed in Oromia population followed by Amhara population, while more unique alleles have been seen among germplasm from Tigray followed by SNNP. The agro-ecologies of Oromia in terms soil types, rainfall pattern, altitude ranges and other socio-cultural diversities favor the existence of highest barley landrace diversity $[20,55,64]$. This could be associated with socio-cultural values of the community in the highland where barley is a sole food crop $[69,70]$.

In general, the diversity observed within barley accessions included in the study indicated that it is possible to accommodate large proportion of variation with collection of small representative number of samples. So it is possible to suggest that during sampling concentrating on the accessions is more worth, time saving and costly effective than giving more attention to regions. However, because of some traits which are region specific still regions are important depending on target traits of selection. Regions like Harerge where drought prevails heading and maturity date was important from farmers 'point of view to select for early matured landraces to produce some grains while for Shewa and Sidama thousand seed weight plays major role since farmers need barley for market and no problem of moisture stress for barley growing areas.

\section{Temporal patterns of genetic variation}

Genetic diversity was studied among different barley landraces portioned in four categories based on years of collection and relative fluctuation in genetic differentiation parameters from Year I to IV was observed. According to Ozbek et al. [71] research report on emmer wheat, sampling of different genotypes that accommodate the same 
Table 6 Genetic distance (below diagonal), and within category expected heterozygosity and the proportion of membership of the samples in each of the clusters obtained at the best $\mathrm{K}(K=3)$

\begin{tabular}{|c|c|c|c|c|c|}
\hline & \multicolumn{5}{|c|}{ Nei genetic distance } \\
\hline & Amhara & Oromia & SNNP & Tigray & B/Gumuz \\
\hline Amhara & - & & & & \\
\hline Oromia & 0.159 & - & & & \\
\hline SNNP & 0.067 & 0.055 & - & & \\
\hline Tigray & 0.139 & 0.060 & 0.032 & - & \\
\hline \multirow[t]{2}{*}{ B/Gumuz } & 0.020 & 0.139 & 0.150 & 0.025 & - \\
\hline & Class I & Class II & Class III & Class IV & \\
\hline Altitude* class I & - & & & & \\
\hline Altitude class II & 0.038 & - & & & \\
\hline Altitude class III & 0.040 & 0.060 & - & & \\
\hline \multirow[t]{2}{*}{ Altitude class IV } & 0.014 & 0.029 & 0.053 & - & \\
\hline & Cluster I & Cluster II & Cluster III & & \\
\hline Cluster I & - & & & & \\
\hline Cluster II & 0.037 & - & & & \\
\hline Cluster III & 0.302 & 0.046 & - & & \\
\hline
\end{tabular}

He expected heterozygosity, Pm proportion of membership, DAPC discriminate analysis of principal components

* Altitude class I ( $\leq 1500 \mathrm{~m})$, Altitude class II (1501-2000 m), Altitude class III (2001-2500 m) and Altitude class III (>2500 m)

sampling point, mutation, and migration of different genotypes from neighboring sites might contribute to the small temporal changes.

However, the effect of mutations can account only for a small number of changes. Migration of genotypes from a neighboring site can also account for some of the changes as pollen and seeds are not usually dispersed far from their mother plant [72]. Thus, a reasonable explanation for the changes between these four decades categories in the present study could be that several genotypes grew around the sampling points and that the relative frequency of every genotype changed between the year categories (also within same category itself) due to variation in environmental factors such as fluctuations in the amount and distribution of the annual rainfall. The effects of such demographic fluctuations were reported by Noy-Meir et al. [73] on emmer wheat.

Furthermore, the effect of changes in plant density in different years, recolonization of "empty" spaces due to relative drought in previous year(s) due to the germination of dormant seeds of other genotypes and the degree of genotype shifts between years at individual sampling points contribute to the temporal changes [74, 75]. In general, environmental factors that have large effects on the fluctuation of demographic processes in space and time, and thus on population dynamics, are often important selective forces affecting genetic composition and its spatio-temporal variation [73]. The positive and highly significant correlation between the between population diversity value of year categories (Year-I to Year-IV) in the current study, indicates closely similar trend of spatial differentiation in all the years.

\section{Population clusters and genetic relationship}

In the present study, the model-based structure analyses using STRUCTURE software [76] and discriminant analysis of principal component (DAPC) revealed the presence of three clusters of barley landraces based on regions of origin, altitude and collection years. Barley landraces used in this study observed to have share ancestry with germplasm from neighboring geographic origins and as a result the three model based clusters were significantly differentiated by SSR markers with $\mathrm{F}_{\mathrm{ST}}$ values ranging from 0.033 (between Amhara and Oromia) to 0.348 (between Tigray and $\mathrm{B} /$ Gumuz) based on regions of origin and 0.021 (between Altitude class III and IV) to 0.307 (between Altitude class I and IV) in terms of altitude classes (Table 6).

The important evolutionary factors that affect the extent of population differentiation are gene flow, genetic drift and selection. Significant geographic differentiation was observed among landraces at various levels of predefined geographic origin, but a large portion of variation was among landraces within rather than between predefined populations (zones and districts). The low-tomoderate geographic differentiation could be attributed to frequent gene flow among barley cultivating farmers as a result of seed exchanges among farmers, and/or to 


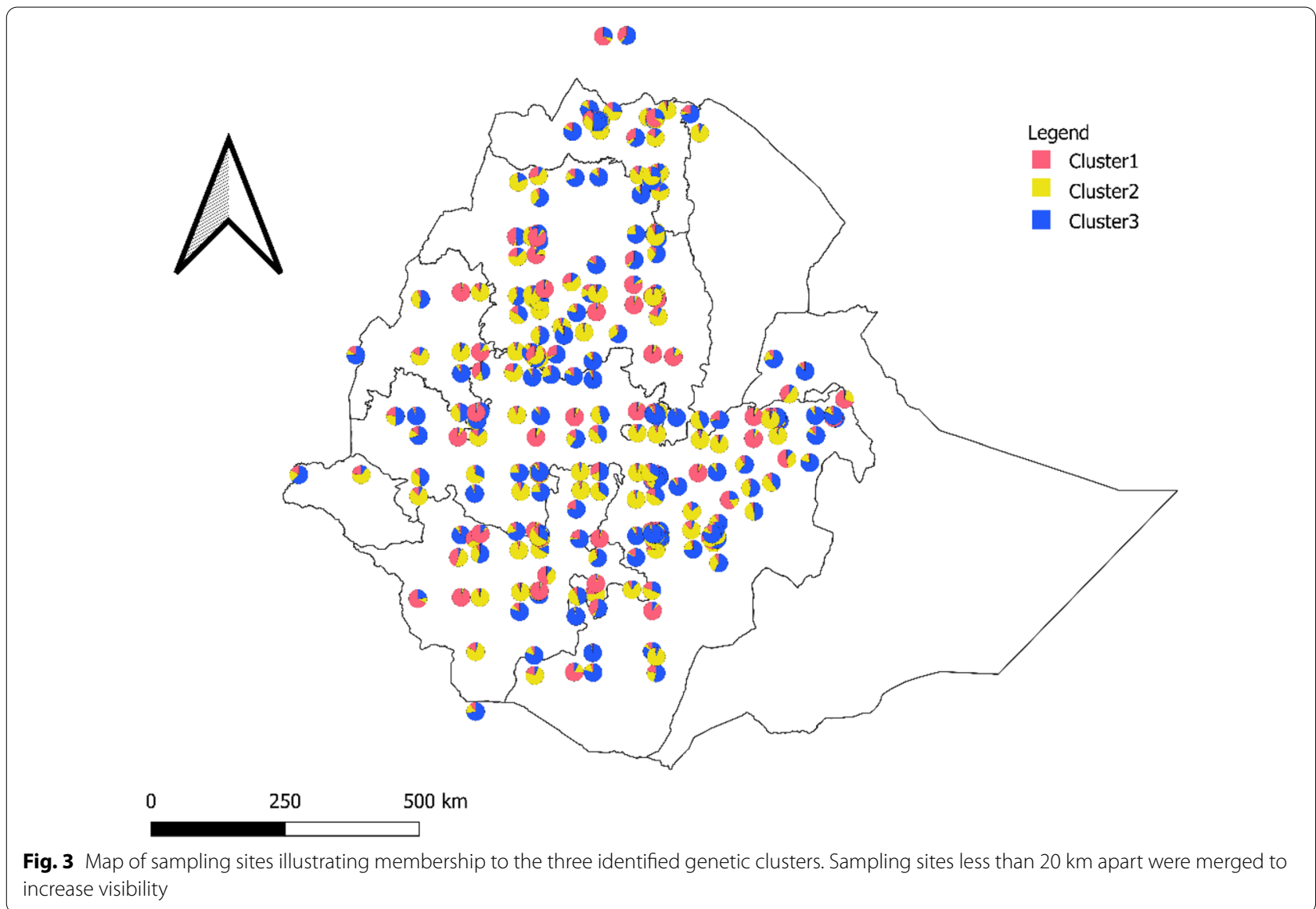

restriction of the intensity of genetic drift due to a high effective population size [77]. Earlier observations on barley by Abebe et al. [78] and on sorghum by Shewayrga et al. [79] showed that several landraces with the same local name are grown in two or more zones attributed to the existing farmers' seed system. Seeds are shared through gift, exchange in kind and purchase. Thus, low differentiations between landraces from different geographic regions have been confirmed in previous studies on barley [78, 80, 81].

Furthermore, in the present study, as shown in Fig. 3, the population structure analysis based on both regions and altitude classes showed no clear clustering pattern or distinct grouping and none of the populations showed a strong probability of belonging to a specific region. According to Falush et al. [82], such phenomenon was explained as, if degree of admixture is close to zero, most individuals are essentially from one population or another; whereas, an admixture (alpha) value of 1 indicates that most individuals carry alleles that make it difficult to assign them to a particular subpopulation.

Therefore, the results obtained in the present study confirmed the absence of geographical structure. In previous research, Abebe et al. [78] reported that based on the regions of origin, the existence of 16 subpopulations with extensive admixture, and the mixed genetic background suggested that the individuals shared the same ancestry, which was related to the high gene flow in the contemporary period among the studied regions. Moreover, the presence of many subpopulations with admixture is an indication for the absence of real population structure.

\section{Relative importance of spatial and temporal factors in maintaining population polymorphism}

The relative genetic diversity and the divergence estimates between the five barley populations (Amhara, Oromia, Tigray, SNNP, B/Gumuz) were significantly larger than the estimates between year categories. Our findings are relevant to geographically closely related barley populations and to temporal effect during the last 41 years. However, similar evidence that the spatial diversity and divergence are larger than the temporal ones in wild emmer populations that are not geographically closely related were reported by Nevo et al. [75] using allozymes, Felsenburg et al. [74] using HMW-glutenins, and Jaradat 
$[83,84]$ using allozymes and HMW-glutenins. Thus, spatial factors account for the main portions of the population genetic variation, suggesting strong provenance specificity and definitely are more important than temporal ones in maintaining genetic variation in barley populations. Similar results were reported also in populations of wild barley $[85,86]$. These results support the prediction of Karlin [87], on the basis of theoretical calculations, that spatial variation is more effective in protecting a polymorphism in a population than temporal variation. For a longer period and large number of samples, however, this may not be necessarily true.

According to the research report in different crops by Feldman and Millet [88], Feldman [89], Huang et al. [90], Hadado et al. [20], and Abebe et al. [55, 78, 80], the genetic variation found in natural populations barley, is very high, much higher than that of domesticated wheat. Hence, genes existing in barley populations may have direct breeding potential and should be conserved at ex situ and on farm. Therefore, detailed information on the genetic structure of populations of crop relatives and its relationship to spatial and temporal factors is imperative for the efficient maintenance of their germplasm. It provides a scientific base for rational guidelines for a detailed monitoring of variation patterns in space and time. The information obtained in this work can assist in planning a strategy for germplasm collection mission and also designing in situ conservation for barley genetic resources.

\section{Conclusion and future studies}

From the observed variability in present study, it can be argued that Ethiopian barley landraces have high genetic diversity. From analysis of genetic parameter, there was indication that some areas, for example south-east and northern parts, had a high level of diversity with more private alleles than other areas of the country. However, the central highland had lower diversity than the eastern and southern highlands. Overall, however, the genetic diversity of barley landraces was widely distributed across barley growing region of the country. This diversity can be exploited for improvement of barley in the area through incorporating landraces in the breeding program as donor parents for traits of interest. Hence, additional systematic screening of barley landraces would be important to identify potential parents that can be used to develop improved varieties that meet the needs of farmers.

\section{Abbreviations}

AMOVA: Analysis of molecular variance; CTAB: Cetyl trimethyl ammonium bromide; DAPC: Discriminate analysis of principal component; DNA: Deoxyribo nucleic acid; EBI: Ethiopian Biodiversity Institute; IBD: Isolation by distance; MAF: Major allele frequency; PCA: Principal component analysis; PCoA: Principal coordinate analysis; PIC: Polymorphic information content; PPL: Percentage of polymorphic loci; SARC: Sinana Agricultural Research Center; SNNP: Southern nation, nationalities and people; SSR: Simple sequence repeat; UPGMA: Unweighted pair group method with arithmetic mea.

\section{Supplementary Information}

The online version contains supplementary material available at https://doi. org/10.1186/s40066-021-00336-3.

Additional file 1: Table S1. Permutation-based multivariate analysis of variance to determine the percentage of variance explained by the effects of sampling sites, year of sampling and their interaction on the matrix of PCA-based genetic distance. Significance was assessed using 9,999 permutations.'

\section{Acknowledgements}

The authors are indebted to numerous individuals for valuable suggestions during the development of this project. We would like to thank Ethiopian Biotechnology Institute for fully funding the research, Ethiopian Biodiversity Institute (EBI) and Sinana Agricultural Research Center for provision of landraces cultivars, respectively. Mr. Keyru is acknowledged for his technical support in laboratory arrangements, DNA extraction and pertinent data collection processes.

\section{Authors' contributions}

Conceptualization, investigation, data collection analysis and visualization: AAD. Methodology: AAD and KT. Resource and project administration: KT. Supervision: BJKS, MSRK, DTD, KT. Validation: BJKS, KT, DTD, and MSRK. Data analysis: AAD and EA. Writing - original draft: AAD and KT. Reviewing and editing: KT, DTD, BJKS, MSRK and EA. All authors commented on previous versions of the manuscript and finally they read and approved the final manuscript. All authors read and approved the final manuscript.

Funding

Not applicable.

\section{Availability of data and materials}

All lists of materials used (Plant and Markers), data recorded, generated and analyzed during this study are included in this manuscript (as Supplementary Information files).

\section{Declarations}

\section{Ethics approval and consent to participate}

The seeds of barley landraces used in this study were obtained from Ethiopian Biodiversity Institute (EBI) established with the objective to ensure conservation and utilization of the country's biodiversity under Establishment/Amendment! Proclamation No. 120/1998, Ethiopia. Since these studies did not involve endangered or protected species, no specific permissions are required for this material. The authors declared that experimental research works on the plants described in this paper comply with institutional and national guidelines.

\section{Consent for publication}

Not applicable.

\section{Competing interests}

The authors declare that they have no competing interests.

\section{Author details}

${ }^{1}$ Ethiopian Biotechnology Institute, P. O. Box 5954, Addis Ababa, Ethiopia. ${ }^{2}$ K.L.E.F. Department of Bio-Technology, Green Field, Vaddeswaram, Guntur District, Andhra Pradesh 522-502, India. ${ }^{3}$ Ethiopian Institute of Agricultural Research, Melkassa Agricultural Research Centre, Plant Biotechnology Research Program, P. O. Box 436, Adama, Ethiopia. ${ }^{4}$ Institute of Biotechnology 
and Dept. of Microbial Cellular and Molecular Biology, Addis Ababa University, P.O. Box 1176, Addis Ababa, Ethiopia.

\section{Received: 31 March 2021 Accepted: 16 August 2021}

Published online: 23 December 2021

\section{References}

1. Austerlitz F, Mariette S, Machon N, et al. Effects of colonization processes on genetic diversity: differences between annual plants and tree species. Genetics. 2000;154:1309-21.

2. Jump AS, Penuelas J. Running to stand still: adaptation and the response of plants to rapid climate change. Ecol Lett. 2005;8:1010-20.

3. Ray DK, Gerber JS, MacDonald GK, et al. Climate variation explains a third of global crop yield variability. Nat Commun. 2015;6(1):1-9.

4. Bren d'Amour C, Wenz L, Kalkuhl M, et al. Teleconnected food supply shocks. Environ Res Lett. 2016;11:035007.

5. Frison EA, Cherfas J, Hodgkin T. Agricultural biodiversity is essential for a sustainable improvement in food and nutrition security. Sustainability. 2011;3:238-53.

6. Houle D. Comparing evolvability and variability of quantitative traits. Genetics. 1992;130:195-204.

7. Kawecki TJ, Ebert D. Conceptual issues in local adaptation. Ecol Lett 2004;7:1225-41.

8. Fischbeck G, et al. Diversification through breeding. In: von Bothmer R, et al., editors. Diversity in barley (Hordeum vulgare). Amsterdam: Elsevier Science B.V; 2003. p. 29-52.

9. Yahiaoui S, Cuesta-Marcos A, Gracia MP, et al. Spanish barley landraces outperform modern cultivars at low-productivity sites. Plant Breed. 2014;133:218-26.

10. Jones H, Civáň P, Cockram J, et al. Evolutionary history of barley cultivation in Europe revealed by genetic analysis of extant landraces. BMC Evol Biol. 2011;11:320. https://doi.org/10.1186/1471-2148-11-320.

11. Camacho VTC, Maxted N, Scholten M, et al. Defining and identifying crop landraces. Plant Genet Resour Charact Util. 2005;3:373-84.

12. Ceccarelli S. Adaptation to low/high input cultivation. Euphytica. 1996:92:203-14

13. Mercer KL, Perales HR. Evolutionary response of landraces to climate change in centers of crop diversity. Evol Appl. 2010;3:480-93.

14. Jarvis DI, Hodgkin T, Sthapit BR, et al. An heuristic framework for identifying multiple ways of supporting the conservation and use of traditional crop varieties within the agricultural production system. Crit Rev Plant Sci. 2011:30:125-76

15. Bertoldo JG, Meirelles CJL, Guidolin AF, et al. Agronomic potential of genebank landrace elite accessions for common bean. Sci Agric. 2014;71:120-5.

16. Dwivedi SL, Ceccarelli S, Blair MW, et al. Landrace germplasm for improving yield and abiotic stress adaptation. Trends Plant Sci. 2016;21:31-42.

17. Jones H, Lister DL, Bower MA, et al. Approaches and constraints of using existing landraces and extant plant material to understand agricultural spread in prehistory. Plant Genet Resour Charact Util. 2008;6:98-112.

18. Fu YB. Understanding crop genetic diversity under modern plant breeding. Theor Appl Genet. 2015;128(11):2131-42. https://doi.org/10.1007/ s00122-015-2585-y.

19. Mohammadi SA, Sisi NA, Sadeghzadeh B. The influence of breeding history, origin and growth type on population structure of barley as revealed by SSR markers. Sci Rep. 2020;10:19165. https://doi.org/10.1038/ s41598-020-75339-4

20. Hadado TT, Rau D, Bitocchi E, et al. Adaptation and diversity along an altitudinal gradient in Ethiopian barley (Hordeum vulgare L.) landraces revealed by molecular analysis. BMC Plant Biol. 2010;10:121.

21. Ceccarelli S, Grando S. Barley landraces from the Fertile Crescent: a lesson for plant breeders. In: Brush SB, editor. Genes in the field. On farm conservation of crop diversity. Boca Raton: IPGRI/IDRC/Lewis Publishers; 2000. p. 51-75.

22. Comadran J, Ramsay L, MacKenzie K, et al. Patterns of polymorphism and linkage disequilibrium in cultivated barley. Theor Appl Genet. 2011:122:523-31.

23. Malysheva-Otto LV, Ganal MW, Röder MS. Analysis of molecular diversity, population structure and linkage disequilibrium in a worldwide survey of cultivated barley germplasm (Hordeum vulgare L.). BMC Genet. 2006;7:6. https://doi.org/10.1186/1471-2156-7-6.

24. Bellucci E, Bitocchi E, Rau D, et al. Population structure of barley landrace populations and gene-flow with modern varieties. PLOS ONE. 2013:8(12):e83891.

25. Pasam RK, Sharma R, Walther A, et al. Genetic diversity and population structure in a Legacy collection of spring barley landraces adapted to a wide range of climates. PLoS ONE. 2014;9: e116164. https://doi.org/10. 1371/journal.pone.0116164.

26. Russell J, van Zonneveld M, Dawson IK, et al. Genetic diversity and ecological niche modelling of wild Barley: Refugia, large-scale post-LGM range expansion and limited mid-future climate threats? PLoS ONE. 2014;9: e86021. https://doi.org/10.1371/journal.pone.0086021.

27. Palumbo F, Galla G, Barcaccia G. Developing a molecular identification assay of old landraces for the genetic authentication of typical agro-food products: the case study of the Barley'Agordino.' Food Technol Biotechnol. 2017:55:29-39.

28. Hasan M, Odat N, Qrunfeh I, et al. Microsatellite analysis of genetic diversity and population structure of Jordanian barley (Hordeum vulgare L.) reveals genetic polymorphism and divergence associated with inflorescence type. Res Crops. 2018;19:86-96.

29. Rauf S, da Silva JT, Khan AA, et al. Consequences of plant breeding on genetic diversity. Int J Plant Breed. 2010;41:1-21.

30. Allendorf FW, Luikart G. Conservation and the genetics of populations. Malden, MA: Blackwell Publishing; 2007.

31. Parmesan C. Ecological and evolutionary responses to recent climate change. Annu Rev Ecol Evol Syst. 2006;37:637-69.

32. Pauls SU, Nowak C, Balint M, et al. The impact of global climate change on genetic diversity within populations and species. Mol Ecol. 2012;22:925-46. https://doi.org/10.1111/mec.12152.

33. Doyle JJ DNA protocols for plants. In: Hewitt G, Johnson AWB and Young JPW Eds. Molecular techniques in taxonomy. NATO ASI Series H, Cell biology. 1991. vol 57, p. 283-293.

34. Keylock CJ. Simpson diversity and the Shannon-Wiener index as special cases of a generalized entropy. Oikos. 2005;109(1):203-7. https://doi.org/10. $2307 / 3548628$.

35. Nei M. Molecular evolutionary genetics. New York: Columbia University Press; 1987.

36. Nagy S, Poczai P, Cernak I, et al. Piccalc: an online program to calculate polymorphic information content for molecular genetic studies. Biochemical Genet. 2012;50(9-10):670-2.

37. Berg EE, Hamrick JL. Quantification of genetic diversity at allozyme loci. Can J Forest Res. 1997;27(3):415-24. https://doi.org/10.1139/x96-195.

38. El Mousadik A, Petit RJ. High level of genetic differentiation for allelic richness among populations of the argan tree (Argania spinosa (L.) Skeels) endemic to Morocco. Theor Appl Genet. 1996:92(7):832-9.

39. Weir BS, Cockerham CC. Estimating f-statistics for the analysis of population structure. Evolution. 1984;38(6):1358-70. https://doi.org/10.1111/j.15585646.1984.tb05657x.

40. Goudet J, Jombart T. Hierfstat: Estimation and tests of hierarchical Fstatistics. R package version 0.04-22. 2015. https://CRAN.R-proje ct.org/ package-hierfstat.

41. Nei M, Tajima F, Tateno Y. Accuracy of estimated phylogenetic trees from molecular data. J Mol Evol. 1983;19:153-70.

42. Sudhir K, Glen S, Michael L, et al. MEGA X: molecular evolutionary genetics analysis across computing platforms. Mol Biol Evol. 2018;35:1547-9.

43. Jombart T. Adegenet: a R package for the multivariate analysis of genetic markers. Bioinformatics. 2008;24(11):1403-5. https://doi.org/10.1093/bioin formatics/btn129.

44. Peakall R, Smouse PE. GenAlEx 6.5 genetic analysis in excel. Population genetic software for teaching and research-an update. Bioinformatics. 2012;28:2537-9.

45. Kamvar ZN, Tabima JF, Grünwald NJ. Poppr: an R package for genetic analysis of populations with clonal, partially clonal, and/or sexual reproduction. Peer J. 2014;2:e281.

46. Wright S. The genetical structure of populations. Ann Hum Genet. 1951;15:323-54

47. Oksanen J, Blanchet FG, Friendly $M$, et al. Vegan: community ecology package. R package version 2.4-2. 2017. Retrieved from https://CRAN.Rproje ct.org/package $=$ vegan 
48. Paradis E. pegas: an R package for population genetics with an integrated-modular approach. Bioinformatics. 2010;26(3):419-20. https:// doi.org/10.1093/bioinformatics/btp696.

49. Whitlock MC. Temporal fluctuations in demographic parameters and the genetic variance among populations. Evolution. 1992;46(3):608-15. https://doi.org/10.2307/2409631.

50. Dray S, Dufour AB. The ade4 package: implementing the duality diagram for ecologists. J Stat Softw. 2007;22(4):1-20. https://doi.org/10.18637/jss. v022.i04.

51. Storfer A, Murphy MA, Evans JS, et al. Putting the "landscape" in landscape genetics. Heredity. 2007;98(3):128-42. https://doi.org/10.1038/sj.hdy. 6800917.

52. Jombart T, Devillard S, Dufour AB, et al. Revealing cryptic spatial patterns in genetic variability by a new multivariate method. Heredity. 2008;101(1):92-103.

53. Moran PAP. The interpretation of statistical maps. J R Stat Soc Ser B Stat Methodol. 1948;10(2):243-51. https://doi.org/10.1111/j.2517-6161.1948. tb00012.x.

54. Botstein $\mathrm{D}$, White $\mathrm{RL}$, Skalnick MH, et al. Construction of a genetic linkage map in man using restriction fragment length polymorphism. Am J Hum Genet. 1980;32:314-31.

55. Abebe TD, Bauer AM, Léon J. Morphological diversity of Ethiopian barleys (Hordeum vulgare L.) in relation to geographic regions and altitudes. Hereditas. 2010;147:154-64.

56. Dido AA, Dawit TD, Krishna MSR, et al. Agro-morphological variability and characters association in barley (Hordeum vulgare L.) landraces differing for maturity period. Res Crops. 2020;21(1):36-45. https://doi.org/10. 31830/2348-7542.2020.006.

57. Dido AA, Krishna MSR, Singh BJK, et al. Assessment of variability of yield affecting metric characters in barley (Hordeum vulgare) landraces. Res Crops. 2020;21(3):587-94. https://doi.org/10.31830/2348-7542.2020.092

58. Dido AA, Singh BJK, Degefu DT, et al. Diversity and resistance components analysis of barley landraces to barley shoot fly (Delia flavibasis). J Plant Dis Prot. 2020. https://doi.org/10.1007/s41348-020-00364-4.

59. Dido AA, Degefu DT, Singh BJK, et al. Multivariate analysis of quantitative characters variability in Ethiopian barley (Hordeum vulgare L.) landrace: based on regions and altitude. Genetika. 2020;52(2):597-620.

60. Allo AD, Kassahun T, Krishna MSR, et al. Phenotypic diversity and population structure of Ethiopian barley (Hordeum vulgare L.) landrace collections. Int J Adv Res Biol Sci. 2020;7(12):144-61. https://doi.org/10.22192/ijarbs.2020.07.12.017.

61. Dido AA, Singh BJK, Krishna MSR, et al. Variability analysis for qualitative characters in Ethiopian barley (Hordeum vulgare L.) landraces. Res Crops. 2020;21(2):355-63. https://doi.org/10.31830/2348-7542.2020.060.

62. Dido AA, Krishna MSR, Singh BJK, et al. Study on variability in resistance to barley yellow dwarf virus (BYDV-PAV) among Ethiopian barley (Hordeum vulgare L.) landraces. Indian Phytopathol. 2021. https://doi.org/10.1007/ s42360-020-00296-x.

63. Dido AA, Tesfaye K, Krishna MSR, et al. Diversity within and among Ethiopian barley (Hordeum vulgare $\mathrm{L}$ ) landraces in resistance to barley net blotch (Pyrenophora teres F. teres (Ptt)). Australas Plant Pathol. 2021. https:// doi.org/10.1007/s13313-020-00764-y.

64. Lakew B, Semeane T, Alemayehu F, et al. Exploiting the diversity of barley landraces in Ethiopia. Genet Resour Crop Evol. 1997:44:109-16.

65. Semeane Y, Lakew B, Alemayu F, et al. Variation in Ethiopian barley landrace populations for resistance to barley leaf scald and net blotch. Plant Breeding. 1998;117:419-23.

66. Hadado TT, Rau D, Bitocchi E, et al. Genetic diversity of barley (Hordeum vulgare L.) landraces from the central highlands of Ethiopia: comparison between the Belg and Meher growing seasons using morphological traits. Genet Resour Crop Evol. 2009:56:1131-48.

67. Adugna A. Assessment of yield stability in sorghum using univariate and multivariate statistical approaches. Hereditas. 2008;145:28-37.

68. Marame F, Dessalegn L, Fininsa C, et al. Genetic analysis for some plant and fruit traits and its implication for a breeding program of hot pepper (Capsicum annuum var. annuum L.). Hereditas. 2009;146:131-40.

69. Asfaw Z. An Ethnobotanical study of barley in the central highlands of Ethiopia. Biol Zent BI. 1990;109:51-62.
70. Shewayrga H, Sopade PA. Ethnobotany, diverse food uses, claimed health benefits and implications on conservation of barley landraces in North Eastern Ethiopia highlands. J Ethnobiol and Ethnomed. 2011;7:19.

71. Ozbek O, Millet E, Anikster Y, et al. Spatio-temporal genetic variation in populations of wild emmer wheat, Triticum turgidum ssp. dicoccoides, as revealed by AFLP analysis. Theor Appl Genet. 2007;115:19-26. https://doi. org/10.1007/s00122-007-0536-y.

72. Golenberg EM. Outcrossing rates and their relationship to phenology Theor Appl Genet. 1988;75:937-44.

73. Noy-Meir I, Agami M, Anikster Y. Changes in the population density of wild emmer wheat (Triticum turgidum var. dicoccoides) in a Mediterranean grassland. Isr J Bot. 1991;40:385-95.

74. Felsenburg T, Levy AA, Galili G, et al. Polymorphism of high- molecular weight glutenins in wild tetraploid wheat: spatial and temporal variation in a native site. Isr J Bot. 1991;40:451-79.

75. Nevo E, Noy-Meir I, Beiles A, et al. Natural selection of allozyme polymorphisms: micro-geographical spatial and temporal ecological differentiations in wild emmer wheat. Isr J Bot. 1991:40:419-49.

76. Pritchard JK, Stephens M, Donnelly P. Inference of population structure using multilocus genotype data. Genetics. 2000;155:945-59.

77. Wang J, Santiago E, Caballero A. Prediction and estimation of effective population size. Rev Hered. 2016;117:193-206. https://doi.org/10.1038/ hdy.2016.43.

78. Abebe TD, Leon J. Spatial and temporal genetic analyses of Ethiopian barley (Hordeum vulgare L.) landraces reveal the absence of a distinct population structure. Genet Resour Crop Evol. 2013;60:1547-58. https:// doi.org/10.1007/s10722-012-9941-4.

79. Shewayrga H, Jordan DR, Godwin ID. Genetic erosion and changes in distribution of sorghum (Sorghum bicolor L. Moench) landraces in NorthEastern Ethiopia. Plant Genet Resour. 2008;6(1):1-10.

80. Abebe TD, Boby M, Leon J. Barrier analysis detected genetic discontinuity among Ethiopian barley (Hordeum vulgare L.) landraces due to landscape and human mobility on gene flow. Genet Resour Crop Evol. 2013;60:297309. https://doi.org/10.1007/s10722-012-9834-6.

81. Abebe TD, Naz AA, Léon J. Landscape genomics reveal signatures of local adaptation in barley (Hordeum vulgare L.). Front Plant Sci. 2015;6:813. https://doi.org/10.3389/fpls.2015.00813.

82. Falush D, Stephens M, Pritchard JK. Inference of population structure using multilocus genotype data: linked loci and correlated allele frequencies. Genetics. 2003;164:1567-87.

83. Jaradat AA. Spatial and temporal genetic structure of wild emmer wheat in Jordan. I. Phenotypic traits. Isr J Plant Sci. 2001;49:S-53-S-64.

84. Jaradat AA. Spatial and temporal genetic structure of wild emmer wheat in Jordan. II. High-molecular weight glutenins and allozymes. Isr J Plant Sci. 2001;49:S-65-S-76.

85. Turpeinen T, Tenhala T, Manninen O, et al. Microsatellite diversity associated with ecological factors in Hordeum spontaneum in Israel. Mol Ecol. 2001;10:1577-91.

86. Turpeinen T, Vanhala T, Nevo E, et al. AFLP genetic polymorphism in wild barley (Hordeum spontaneum) populations in Israel. Theor Appl Genet. 2003;106:1333-9.

87. Karlin S. Classifications of selection-migration structures and conditions for a protected polymorphism. Evol Biol. 1982;14:61-204.

88. Feldman F, Millet E. Methodologies for identification, allocation and transfer of quantitative genes from wild emmer into cultivated wheat In: Proceedings of 8th international wheat genetic symposium, Beijing, China; 1995. p. 19-27.

89. Feldman M. The origin of cultivated wheat. In: Bonjean AP, Angus WJ, editors. The world wheat book. Paris: Lavoisier Tech and Doc; 2001. p. 3-56.

90. Huang L, Millet E, Rong JK, et al. Restriction fragment length polymorphism in wild and cultivated tetraploid wheat. Isr J PI Sci. 1999;47:213-24.

\section{Publisher's Note}

Springer Nature remains neutral with regard to jurisdictional claims in published maps and institutional affiliations. 